\title{
LETTER
}

\section{Meiotic segregation analysis by FISH investigations in sperm and spermatocytes of translocation heterozygotes}

\author{
Susan J A rmstrong ${ }^{1}$ and M aj A Hultén ${ }^{2}$ \\ ${ }^{1}$ School of Biological Sciences, U niversity of Birmingham \\ ${ }^{2}$ D epartment of Biological Sciences, University of Warwick, UK
}

It has been repeatedly claimed that in translocation heterozygotes information on meiotic analysis may be obtained via sperm investigations, either by karyotyping (for reviews see $\mathrm{M}$ artin, ${ }^{1} \mathrm{E}$ sto ${ }^{2}$ ) or FISH of sperm nuclei. This is exemplified by the recent paper ${ }^{3}$ in this journal entitled 'The meiotic segregation pattern of a

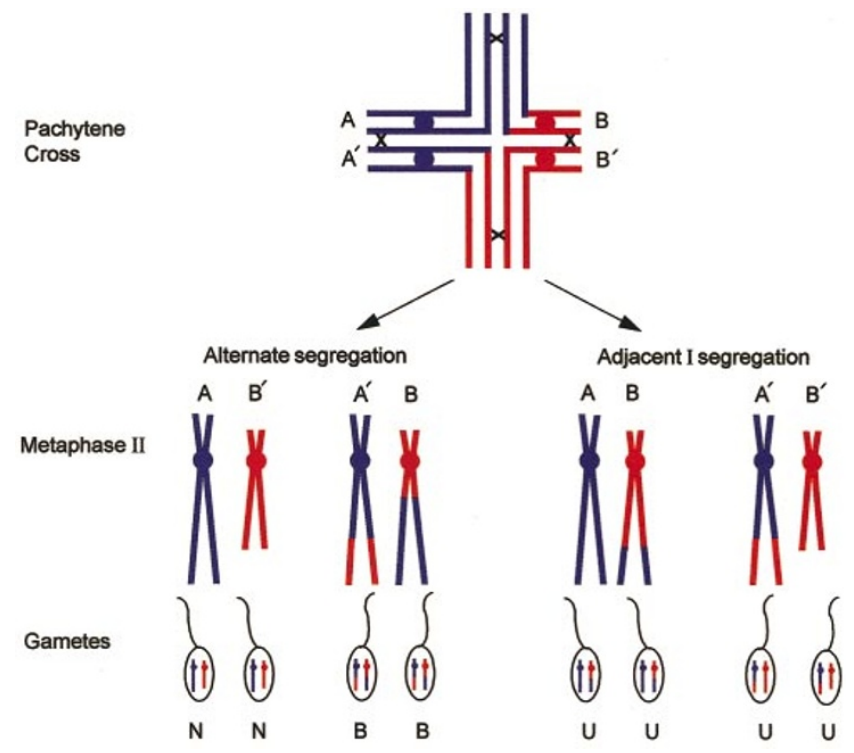

Figure 1(a) Outcome of first meiotic segregation with no interstitial chiasmata. A Iternate segregation produces $50 \%$ balanced (B ) products (sperm), whereas A djacent I segregation produces $100 \%$ unbalanced $(U)$ products. Note: using centromeric probes alone will not distinguish between these products.

Correspondence: Prof M A H ultén, D epartment of Biological Sciences, U niversity of Warwick, Warwick, CV $47 A$ L, U K Tel: 01203-528976; E-mail ceht@dna.bio.warwick.ac.uk

R eceived 15 October 1997; revised 16 February 1998; accepted 25 February 1998 reciprocal translocation $\mathrm{t}(10 ; 12)$ (q26.1;p 13.3) by fluorescence in situ hybridization sperm analysis', where it is stated that 'adjacent I segregation predominates in many translocation carriers'. This is not a valid statement due to the limitations of FISH of sperm for obtaining information on meiotic segregation patterns of reciprocal translocations. Firstly, only data on adjacent II and the infrequent categories of 3:1 and 4:0 segregants can be identified, if using centromeric probes. Further, even if telomeric probes are used, it is

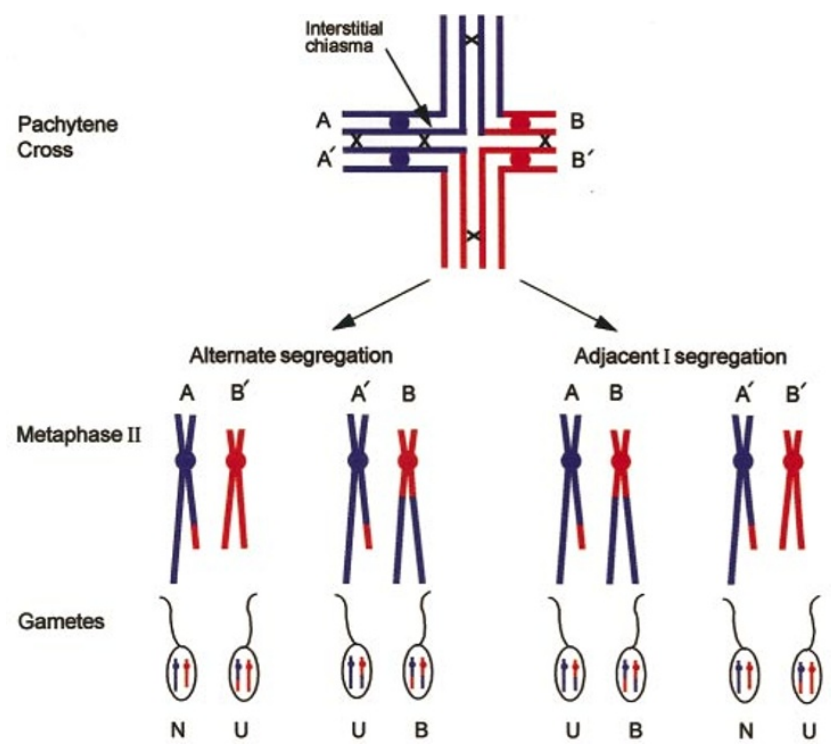

Figure 1(b) O utcome of first meiotic segregation with interstitial chiasma. A Iternate segregation produces $25 \%$ normal, $25 \%$ unbalanced and $50 \%$ unbalanced gametes. A djacent I segregation produces the same frequencies. Note: even if probes are used distal to the breakpoint, it is not possible to determine their origin, either A Iternate or A djacent I category of segregation. 
still not possible to tell whether the gametes were derived from adjacent I or alternate segregations, where this is complicated by an interstitial chiasma.

It is a well known fact, and is clearly stated in many publications, including textbooks, ${ }^{4,5}$ that whenever an interstitial chiasma is present, asymmetric dyads are produced at anaphase I. These could be derived from either alternate or adjacent I segregations. Thus anaphase II products of these segregations will be $25 \%$ normal, 25\% balanced and 50\% unbalanced. This is in contrast to the situation without an interstitial chiasma, as illustrated in Figure 1.

$\mathrm{U}$ sing FISH on testicular biopsies, we have examined four reciprocal translocation carriers. ${ }^{4,6,7}$ A nalysis of metaphase I demonstrated that the reciprocal translocation chromosomes regularly form quadrivalents as is generally the case, even when the translocated segments are very small. M ost importantly, there is a high frequency of a single chiasma within the interstitial segments. This was found in no less than $48 \%$ for the $t(1 ; 11), 31 \%$ for the $t(15 ; 20), 95 \%$ for the $t(11 ; 22)$ and $100 \%$ for the $t(9 ; 21)$ translocation heterozygotes. $4,6,7$ These frequencies are substantially increased in comparison to chiasma formation within these segments in the normal male. ${ }^{8} \mathrm{~A}$ dequate information on the occurrence of chiasmata within the interstitial segments can only be obtained by meiotic studies of the respective translocation carriers. U sing FISH it has been possible to identify the interstitial chiasma frequency and resultant asymmetric dyads. This analysis thus differentiates between the three categories: (1) alternate, (2) adjacent I and (3) alternate/adjacent I. However, it is important to note that even FISH meiotic studies do not allow us to state whether alternate or adjacent I segregation predominates in male translocation carriers!

\section{References}

$1 \mathrm{M}$ artin R H, Spriggs, E L : Sperm chromosome complements in a man heterozygous for a reciprocal translocation $46, X Y$, $t(9 ; 13)(q 21.1 ; q 21.2)$ and a review of the literature. Clin G enet 1993; 47: 42-46.

2 E stop A M, Van K irk V, Cieply K : Segregation analysis of four translocations, $\mathrm{t}(2 ; 18), \mathrm{t}(3 ; 15), \mathrm{t}(5 ; 7)$ and $\mathrm{t}(10 ; 12)$, by sperm chromosome studies and a review of the literature. Cytogenet Cell G enet 1995; 70: 80-87.

3 E stop A M, Cieply K M , A ston CE : The meiotic segregation pattern of a reciprocal translocation $\mathrm{t}(10 ; 12)$ (q26.1;p13.3) by fluorescence in situ hybridisation sperm analysis. E ur J H um Genet 1997; 5: 78-82.

4 G oldman A SH, H ultén M A : A nalysis of chiasma frequency and first meiotic segregation in a human male reciprocal translocation heterozygote, $\mathrm{t}(1 ; 11)$ ( $p 36.3 ; \mathrm{q} 13.1)$ using fluorescence in situ hybridisation. Cytogenet Cell Genet 1993; 63: 16-23.

$5 \mathrm{H}$ ammerton JL: Human Cytogenetics, vol 1. A cademic Press: L ondon, 1971.

6 Goldman A SH, H ultén M A : M eiotic analysis by FISH of a human male $46, X Y, t(15 ; 20)(q 11.2 ; q 11.2)$ translocation heterozygote:quadrivalent configuration, orientation and first meiotic segregation. Chromosoma 1993; 102: 102-111.

7 A rmstrong SJ, Goldman A SH, Hultén MA: Segregation analysis in human reciprocal translocation carriers using FISH. Chromosome Res 1995; 3: suppl. 1, 109 (A bstr.)

$8 \mathrm{Hultén}$ MA: Chiasma distribution at diakinesis in the normal human male. Hereditas 1974; 76: 55-78. 